\title{
O ensino de línguas estrangeiras no Colégio de Aplicação da UFRGS - destaque para a língua alemã
}

Rosita Maria Schmitz*

Resumo: Este relato trata dos principais movimentos que aconteceram no ensino de línguas estrangeiras no Colégio de Aplicação da UFRGS, especialmente a partir de 2008, com a elaboração de projetos pelos professores da Área de Línguas Estrangeiras do Departamento de Comunicação, principalmente no que se refere à ampliação da carga horária. A forma como é feita a escolha da língua estrangeira na sétima série do Ensino Fundamental e no Ensino Médio também é abordada. Apresenta-se, também, os principais objetivos a serem alcançados depois da assinatura de um termo de cooperação entre o CAp e o Goethe-Institut de São Paulo, para incentivar o estudo da Língua Alemã. Nos depoimentos de alunos - nos quais eles justificam sua opção pelo estudo de outro idioma, ressaltando a importância do convênio entre o Colégio de Aplicação e o projeto PASCH, Escolas: uma parceria para o futuro - percebe-se o acerto da iniciativa.

Palavras-chave: Línguas estrangeiras; Carga horária; Escolas parceiras; Depoimentos.

Zusammenfassung: Dieser Bericht handelt von den wichtigsten Änderungen, die im Bereich der Fremdsprachen an der Aplicação Schule der UFRGS, hautpsächlich seit 2008, mit der Aufstellung von Projekten durch die Fremdsprachenlehrer

Professora de Língua Alemã do Colégio de Aplicação da UFRGS, Mestre em Literatura Alemã e História. E-mail: rositams@hotmail.com 
der Kommunikationsabteilung statt gefunden haben. Es geht hauptsächlich um die Erweiterung des Fremdsprachenunterrichts. Wie Schüler der 7. Klasse der Grundschule und der Oberstufe die Sprache wählen wird auch erklärt. Die wichtigsten Ziele, die nach dem Kooperationsvertrag zwischen der CAp und des Goethe-Instituts São Paulo erreicht werden sollen, um die deutsche Sprache zu fördern, werden hier angesprochen. In den Berichten von Deutschlernenden, in denen sie ihre Wahl begründen und die die Wichtigkeit des Abkommens zwischen der Schule und PASCH, Schulen: Partner der Zukunft hervorheben, wird die Richtigkeit der Initiative bestätigt.

Schlüsselwörter: Fremdsprachen; Unterrichtsstunden; Partnerschulen; Berichte.

\section{Introdução}

O Colégio de Aplicação, desde sua fundação em 1954, vem desenvolvendo e implementando novas propostas pedagógicas. Essa instituição tem sido pioneira em relação às propostas de trabalho em muitas áreas, dentre elas, destaca-se o ensino da Música e das Línguas Estrangeiras nas séries iniciais, e também o oferecimento de Língua Alemã, Inglesa, Francesa e Espanhola como integrantes do currículo.

No primeiros anos, o currículo era composto de Ginásio e Ensino Médio, e a língua estrangeira ministrada era a Língua Inglesa. A partir de 1977, os alunos da $7^{\mathrm{a}}$ e $8^{\mathrm{a}}$ séries passaram a optar por uma segunda língua: Alemão e Francês. Em 1992 deu-se início ao ensino da Língua Espanhola nas séries finais do Ensino Fundamental.

Nos últimos anos, o Departamento de Comunicação do CAp propôs a reformulação do currículo. Assim, intensificou seus esforços no sentido de inovar suas práticas pedagógicas, tornando o ensino de línguas estrangeiras mais significativo para o aluno e ampliando o tempo de ensino, não apenas estendendo seu acesso a outras séries, mas também aumentando a carga horária. 
O ano de 2008 foi decisivo para a Área de Línguas Estrangeiras do Colégio de Aplicação. Nesse ano, foram criados projetos para aumentar a carga horária dessas disciplinas e para estender seu ensino a todos os níveis. Até 2008, a disciplina de Língua Alemã era oferecida na grade curricular de $7^{\mathrm{a}}$ e $8^{\mathrm{a}}$ séries, perfazendo um total de $2 \mathrm{~h} / \mathrm{a}$ semanais, em caráter optativo. Além disso, o CAp assinou um Termo de Cooperação com o projeto Schulen: Partner der Zukunft (PASCH), Escolas: uma parceria para o futuro, vinculado ao Ministério das Relações Exteriores da República Federal da Alemanha, ao Goethe-Institut e a outras Instituições alemãs ligadas ao ensino e à cultura. Este relato se baseia no que consta nos projetos intitulados Ampliação da oferta e da carga horária de língua estrangeira no Colégio de Aplicação da UFRGS (2008) e Ampliação da oferta e da carga horária de Língua Alemã no CAp (2008), assim como no Termo de Cooperação, assinado em fevereiro de 2008, entre o Colégio de Aplicação da Universidade Federal do Rio Grande do Sul e o Goethe-Institut São Paulo.

\section{Objetivo geral das línguas estrangeiras}

O objetivo geral da ampliação da oferta e da carga horária das Línguas no currículo é propiciar ao aluno a competência nas quatro habilidades linguísticas (ouvir, ler, falar e escrever), capacitando-o para o uso efetivo da língua nas mais diversas situações de comunicação e possibilitando a integração da língua estrangeira às demais áreas do conhecimento. Sendo o objetivo principal do processo de ensino e aprendizagem proporcionar atividades em que os alunos estabeleçam uma comunicação eficiente em língua estrangeira, é necessário desenvolver sua competência comunicativa de forma total, trabalhando tanto a expressão oral e escrita, quanto a compreensão auditiva e de leitura em situações de comunicação cotidianas, ou seja, as habilidades linguísticas referidas em determinados contextos sociais e culturais. Assim, a aquisição e o desenvolvimento da competência comunicativa se 
centram na ação do falante como ser social na língua estrangeira, considerando o aluno como núcleo do processo de ensino e aprendizagem. Essa deve ser significativa para o aluno, integrando as quatro habilidades de ler, ouvir, escrever e falar.

As ações, tanto de aprendizagem quanto de comunicação, são o meio mais adequado para os alunos ativarem seus recursos linguísticos e não linguísticos. As atividades de aprendizagem preparam o estudante para poder realizar as operações de comunicação que, ao mesmo tempo, devem corresponder a situações comunicativas reais, de forma que o emprego de uma ou mais habilidades possa responder a necessidades autênticas.

\section{Objetivos específicos}

Ampliando o conhecimento do idioma estrangeiro e compreendendo seu funcionamento, o aluno será levado automaticamente a estabelecer relações entre as diferentes estruturas linguísticas da língua estudada e da língua materna, ajudando-o a compreender melhor a própria língua. Além do desenvolvimento linguístico, o contato com a diversidade cultural transmitida pela língua leva o aluno a um conhecimento e a uma apreciação dos costumes e valores de outras culturas, contribuindo para uma nova percepção da própria cultura, promovendo uma aceitação maior das diferenças.

O conhecimento de um idioma estrangeiro permite também ao aluno acessar informações de diversas áreas do conhecimento, possibilitando o contato direto com a produção de pensadores, escritores e artistas, importantes para o desenvolvimento das artes e das ciências. E, por fim, propiciando o encontro das diferenças nas maneiras de expressão e de comportamento e ampliando as possibilidades de agir discursivamente, $\mathrm{o}$ aluno se tornará um cidadão do mundo.

Busca-se, assim, incentivar o questionamento por parte do aluno, a capacidade de perguntar e não apenas de responder, tornando-o centro do processo educativo de forma a valorizar os 
diferentes estilos de inteligência, bem como os diferentes estilos cognitivos e culturais.

Diante das evidências de que o projeto qualifica o ensino de forma geral e não apenas propicia a aquisição da língua, busca-se estabelecer uma relação dos alunos com o mundo, numa abordagem realmente comunicativa, através de materiais que estimulem a interação, utilizando os recursos tecnológicos existentes, permitindo, assim, o acesso a informaçóes autênticas sobre a cultura e a língua estudadas. Além disso, busca-se fomentar ações de extensão como teatro, intercâmbios e projetos em geral.

Para alcançar esse propósito, a área de Línguas Estrangeiras mantém um Núcleo de intercâmbios, permitindo, dessa forma, que os alunos possam ter uma experiência significativa na sua vida escolar, ampliando seus horizontes culturais e vivenciando a língua estudada junto a falantes nativos. No caso da Língua Inglesa, o Colégio possui um convênio com uma escola norte-americana de Weston, permitindo que alunos do CAp-UFRGS frequentem essa instituição. Da mesma forma, o CAp-UFRGS tem recebido, desde 1961, alunos americanos que manifestam interesse por estudar no Brasil. Desde 2007, o Núcleo de intercâmbios vem tentando ampliar as parcerias como forma de contemplar as demais línguas estudadas pelos alunos. No ano de 2008, alunos do CAp receberam bolsas de estudo para a Alemanha. Graças a essa iniciativa, os estudantes de língua alemã têm a oportunidade de permanecer nesse país por três semanas, conhecendo-o e estudando seu idioma. A partir de 2011, também foi concedida aos alunos do Ensino Médio a possibilidade de estudar durante um mês na cidade de Villa Carlos Paz, na Argentina.

\section{Séries envolvidas e carga horária}

Com as propostas definidas em 2008, a partir de 2009 a escola destina, dentro da proposta curricular de $7^{\mathrm{a}}$ série, $5 \mathrm{~h} / \mathrm{a}$ semanais ao ensino específico de Línguas, e, além disso, oferece 
mais 4h/a semanais de atividades integradas interdisciplinares, utilizando a língua estrangeira como mediação. A disciplina é oferecida dentro de uma proposta plurilíngue, na qual o aluno faz sua escolha a partir da oferta de Língua Alemã, Língua Espanhola, Língua Francesa e Língua Inglesa. Objetiva-se, num futuro próximo, a escolha da língua a partir do sexto ano.

Também a partir de 2009, a oferta de Língua Alemã se estendeu ao Ensino Médio, possibilitando aos alunos que optaram por essa língua na $7^{\mathrm{a}}$ e $8^{\mathrm{a}}$ séries continuar e ampliar seus estudos. A disciplina é oferecida dentro do currículo na forma de Disciplina Eletiva, com 2h/a semanais.

Com a efetivação de dois professores concursados em 2010, a implementação da segunda fase do projeto para a extensão da Língua Alemã ao Ensino Médio foi concretizada. Os alunos do Ensino Médio inscritos na disciplina, da mesma forma que os de $7^{\mathrm{a}}$ e $8^{\mathrm{a}}$ séries, participarão do Projeto Escolas: uma parceria para o futuro.

\section{Projeto Escolas: uma parceria para o futuro}

Em todo o mundo, há pessoas estudando alemão - por diferentes motivos. Frequentemente, professores e multiplicadores do idioma precisam apresentar bons argumentos para convencer estudantes e diretores de escolas da importância do aprendizado do idioma alemão. É preciso desenvolver argumentos baseados em políticas educacionais que justifiquem sua manutenção ou inclusão nos currículos. Para estimular a curiosidade e a motivação continuadas dos estudantes, criou-se uma parceria com escolas do mundo inteiro, para construir ligações vivas e de longo prazo com a Alemanha.

O contexto do projeto Escolas: uma parceria para of futuro foi concebido pelo Ministro das Relações Exteriores da Alemanha, Dr. Frank-Walter Steinmeier, tendo como objetivo inicial 
criar uma rede mundial de pelo menos 1000 escolas parceiras. Atualmente a rede de escolas PASCH conta com 1500 escolas parceiras e 23 novas Escolas Alemãs no Exterior passarão a integrar o Programa, além de centenas de outras que oferecerão certificados de proficiência ou que passam a contar com o idioma alemão nos currículos. Sua finalidade não é apenas possibilitar o acesso de alunas e alunos ao idioma alemão, mas despertar o interesse e o entusiasmo dos jovens pela Alemanha de hoje e de sua sociedade.

Para viabilizar esse projeto, o Ministério das Relações Exteriores da Alemanha (Auswärtiges Amt) trabalha em conjunto com o Departamento Central para o Ensino de Alemão no Exterior (ZfA), o Goethe-Institut, o Serviço Alemão de Intercâmbio Pedagógico e o Serviço Alemão de Intercâmbio Acadêmico (DAAD). Essa iniciativa pretende, através de subsídios financeiros e técnicos, fortalecer e ampliar a rede de escolas parceiras da Alemanha no Exterior, assim como intensificar a cooperação entre essas escolas para a consolidação do ensino de alemão como língua estrangeira no currículo escolar. Além disso, serão criados vínculos produtivos e permanentes entre a Alemanha, as instituições de ensino, professores e alunos, a fim de promover o intercâmbio de ideias e a troca de experiências.

O Goethe-Institut - que é peça chave na formação da rede mundial de escolas parceiras do projeto Escolas: uma parceria para o futuro - é uma organização cultural da República Federal da Alemanha, e está presente em 92 países, com 149 Institutos. Suas atividades incluem a promoção do conhecimento da língua alemã no Exterior, o fomento da colaboração cultural internacional e a transmissão de uma visão abrangente da Alemanha, através de informações sobre a vida política, social e cultural alemã. A rede de Institutos e de Centros Goethe, associações culturais, salas de leitura, assim como os centros de exames e de aprendizagem atuam no âmbito da política cultural e educacional internacional, ao mesmo tempo estabelecendo cooperaçôes com instituições 
culturais privadas e públicas, com municípios, estados e organismos econômicos.

No acordo firmado entre o Ministério das Relações Exteriores da Alemanha, o Colégio de Aplicação e o Goethe-Institut, este se compromete a prestar assistência ao CAp através de subsídios financeiros e técnicos (na medida, proporção e possibilidades definidas), visando à consolidação do ensino de alemão como língua estrangeira no currículo escolar. Serão também criados vínculos produtivos e permanentes entre a Alemanha, o CAp, professores e alunos, a fim de promover o intercâmbio de ideias e a troca de experiências do ensino da língua alemã.

Assim, os alunos de alemão do CAp recebem o material didático destinado ao ensino do idioma, além de materiais didáticos de apoio, destinados aos professores de alemão do colégio. A escola também recebe equipamentos eletrônicos, que são de uso exclusivo para o ensino de alemão. $\mathrm{O}$ aluno, durante o período letivo, terá acesso aos livros e materiais de ensino, mas deve ser orientado a mantê-los íntegros e conservados, para devolvê-los aos professores no término do correspondente período letivo, para que possam ser reutilizados por outros estudantes no ano seguinte.

Todos os semestres, serão oferecidas bolsas de estudos para cursos na Alemanha aos alunos com melhor desempenho, sendo o número total de bolsistas no ano e sua escolha determinados pela Central do Goethe-Institut em Munique. Além dos alunos, também os professores de alemão podem participar de cursos para formação continuada nas áreas de metodologia e didática, cultura e geografia alemãs e língua alemã, tanto no Brasil como na Alemanha.

Os alunos interessados podem, anualmente, prestar exames oficiais de proficiência na língua alemã e participar de competições referentes à língua referida, de acordo com critérios pré-estabelecidos pelo Goethe-Institut. Os estudantes podem igualmente participar de projetos culturais e concursos, reforçando a aplicação de seus conhecimentos do idioma. Para que 
essas práticas sejam devidamente efetuadas, existe a rede www. pasch-net.de, que é um instrumento especialmente importante da conexão e da comunicação para os estudantes e os professores.

Nessa rede, em que são apresentados projetos, os professores podem encontrar materiais diversos para suas aulas, aprimorar seus conhecimentos em língua, metodologia e didática e trocar ideias com colegas na página Community. Os estudantes encontram ali informações sobre temas atuais, assim como concursos e sugestôes para projetos, jogos e exercícios para aperfeiçoar os conhecimentos do idioma. Os alunos igualmente podem se comunicar pela rede, sendo o idioma comum o alemão. Há ainda salas de aula virtuais, nas quais projetos com outras escolas e até de outros países podem ser realizados. Essas salas destinam-se, também, a atividades de aperfeiçoamento e aos seminários, realizados sob orientação dos professores. Nesses locais é possível, ainda, a prática do estudo individualizado.

Juntamente com muitas ofertas alternativas, existem, naquele sítio, jogos pedagógicos e concursos internacionais para alunas e alunos. Professores podem, nessa plataforma, exercitar formas digitais modernas de lecionar, aprender novas metodologias e encontrar ideias e novidades para suas aulas de Língua. $\mathrm{O}$ CAp, por seu lado, se compromete a incluir o ensino de alemão como língua estrangeira no currículo escolar e a mantê-la como língua estrangeira na sua grade curricular após a fase de implementação. Cabe também à escola informar ao Goethe-Institut qualquer alteração no corpo docente responsável pelas aulas de alemão na escola e fornecer dados estatísticos relacionados ao ensino da língua alemã.

O CAp se compromete a permitir que seus professores e alunos se ausentem da instituição para eventos e cursos de formação continuada, relativos ao projeto: Escolas: uma parceria para of futuro, no Brasil e na Alemanha. O Goethe-Institut realiza anualmente cerca de 90 seminários em 18 cidades da Alemanha, exclusivamente para professores de língua alemã que não atuam na Alemanha. Os cursos abrangem desde aperfeiçoamento do 
idioma, mostram como aspectos do cotidiano das pessoas, da cultura e da história contribuem para transmitir uma visão atualizada do país. O CAp também tomará todas as medidas cabíveis para o bom andamento do projeto do Termo de Cooperação, de forma a torná-lo conhecido, empreendendo todos os esforços necessários à boa aprendizagem e à fixação da língua alemã por parte dos seus alunos, bem como a atualização constante de seus professores.

\section{Dados atualizados do PASCH: "Escolas: uma parceria para o futuro"}

Em 2008 e 2009, o Parlamento alemão dispôs 45 milhões de Euros e, em 2010, 54 milhões foram destinados para a iniciativa. Em 2011, estão disponíveis 51 milhões de Euros. O sucesso do PASCH se mostra no interesse crescente pela Alemanha e uma grande procura pela língua alemã. Um dos objetivos do PASCH, que é o de promover trocas entre os participantes do programa, está sendo alcançado. O que se aprende dos e com os outros, assim como o intercâmbio de determinados temas, fortalece a iniciativa PASCH e a comunidade de estudantes. A ressonância positiva desse projeto deixa claro também que através do PASCH faz-se uma oferta altamente qualificada. Isso leva, para além das aulas de Língua Alemã, ao desenvolvimento da escola e ao aprimoramento da formação cultural.

Depois de priorizada, nos anos de 2008 a 2010, a construção da rede de escolas, futuramente a ênfase estará na melhoria da qualidade das aulas, da integração não só das escolas do PASCH entre si, mas também com escolas na Alemanha. Além disso, com esse intercâmbio, espera-se que haja um fortalecimento das relações entre escola, universidade ou profissão.

Neste ano de 2011, o foco está em consolidar a rede, assegurar sua continuidade e aumentar a oferta da Língua Alemã. Para atingir essas metas, reforça-se a rede de contatos entre as escolas e investe-se fortemente na melhoria das aulas. Os 
parceiros da iniciativa desenvolvem uma série de medidas para vitalizar a rede, aumentar sua qualidade e organizá-la de forma a garantir sua continuidade. Além disso, empresas alemãs devem ser integradas de forma crescente, pois, afinal, também elas irão tirar proveito dessa iniciativa. Somente com seu engajamento, a iniciativa pode se desenvolver plenamente. Para isso, existem diversas possibilidades para empresas incentivarem seus parceiros: através de bolsas de estudos ou estágios, auxílio para equipar escolas ou apoiar financeiramente projetos individuais. Afinal, à fantasia não podem ser colocados limites.

\section{Depoimentos de alunos do CAp sobre a opção pela língua alemã}

No início do ano letivo de 2011 , as turmas 71 e $72\left(7^{a}\right.$ série) passaram pelo processo de sensibilização para as línguas estrangeiras, com o intuito de prepará-las para a escolha consciente da língua estrangeira que cursarão até o final da $8^{\mathrm{a}}$ série. No Ensino Médio, os alunos devem escolher um idioma diferente daquele que estudaram nos dois últimos anos do Ensino Fundamental, podendo ainda optar por língua estrangeira como Disciplina Eletiva.

No início do ano letivo, na $7^{\mathrm{a}}$ série, as quatro professoras de línguas estrangeiras (Inglês, Francês, Espanhol e Alemão) entraram em contato com todos os alunos, revezando-se nas turmas, em diferentes atividades. Os alunos trabalharam em grupos, formados por sorteio. Esses grupos tinham como tarefa pesquisar fatores relevantes, tanto da língua, quanto da cultura dos países onde é falada, sua importância no mundo e sua influência no Brasil. Ao final das pesquisas, os trabalhos foram apresentados para todos os grupos. Houve também palestras de professores de fora do CAp e de professores e alunos que participaram de intercâmbios nos Estados Unidos, Espanha, França e Alemanha. 
Depois de um breve contato de todos os alunos da série referida com os quatro idiomas e uma reunião com os pais, os estudantes realizaram sua escolha, justificando sua opção. Pelas respostas dadas pelos alunos, considerou-se que o trabalho de conscientização e valorização das quatro línguas foi efetivo, contribuindo para uma das metas do trabalho realizado no CAp, que é valorizar igualmente todos os idiomas. Abaixo, reproduzse algumas das justificativas dos alunos que optaram pela língua alemã:

Eu escolhi fazer alemão, porque, como eu quero fazer intercâmbio para a Alemanha [...] eu sempre quis fazer alemão, tanto que talvez se eu conseguir quero ir para a Alemanha. Minha família contribuiu para a minha escolha, porque fazer alemão é uma oportunidade que muitas pessoas não têm o privilégio. Eu amo alemão [...] vai ser difícil, mas eu adoro novos desafios. E quero muito viajar para a Alemanha.

Porque hoje em dia é muito difícil encontrar lugar para fazer alemão e se você sabe alemão é mais um diferencial na carreira. [...] e, além disso, a taxa do curso é alta.

Escolhi fazer alemão, $[. .$.$] porque é uma língua que eu venho querendo$ aprender desde a Copa do Mundo da Alemanha, e agora tenho essa oportunidade e não vou desperdiçar.

No Ensino Médio, a escolha da língua estrangeira é feita de forma semelhante à do Ensino Fundamental. A opção, no entanto, é realizada em menos tempo. Por ocasião da escolha, os alunos também justificam sua opção.

Porque eu queria ir para a Alemanha, e achava uma língua muito interessante de aprender, legal e diferente. Mas todas as outras línguas também são boas.

Eu escolhi alemão, pois minha família é de origem alemã, e por interesse em aprender novas línguas, pois tenho bastante contato com espanhol e inglês.

Finalmente, pelos depoimentos e justificativas dados pelos alunos, apresenta-se um relato de uma aluna que participou do 
intercâmbio para a Alemanha em 2011. Sua narrativa gratifica o trabalho realizado com os alunos, incentiva-os a enfrentar os desafios e a tentar derrubar o mito de que alemão é uma língua difícil e impossível de aprender.

Deutschland, Germany, Alemania, Германия, ประเทศเยอรมัน, Alemanha!

Ir para a Alemanha com 15 anos e entrar em contato direto com as mais variadas culturas, de países como Rússia, Indonésia, Austrália, Colômbia e Tailândia foi, sem dúvida, a maior experiência de minha vida até agora e a comprovação de que o esforço nos estudos não é em vão, levando em conta que existem várias exigências para receber a bolsa. Eu fui em janeiro de 2011 e passei três semanas em Frankfurt, dividindo o quarto com três meninas de diferentes nacionalidades. Nós tínhamos aulas durante a manhã e pela tarde e noite fazíamos atividades de integração com o grupo. Durante as três semanas, visitamos museus, patinamos no gelo, assistimos aos jogos de futebol e hockey, tivemos karaokê, festas, jogos e competiçóes em grupo, passeios a outras cidades, compras e várias outras atividades e, se eu pudesse, faria tudo de novo.

Além de aperfeiçoar meus conhecimentos linguísticos no alemão e conhecer pessoas de várias partes do mundo, pude perceber que até aqueles costumes que achamos que todos possuem em comum podem ser tão diferentes, como as formas de se cumprimentar. As pessoas dos outros países achavam os brasileiros meio malucos, pois geralmente quando um brasileiro via o outro abraçava e beijava. Minha colega de quarto da Austrália dizia que isto não era muito frequente no país dela. Dentre os países, o que eu mais achei diferente dos costumes do Brasil foi a Indonésia. A maior parte das meninas usava burca e faziam vários rituais durante a noite ou dia, devido à sua religião. As situações mais engraçadas aconteciam quando não conseguíamos falar algumas coisas em alemão. Aí éramos obrigados a fazer mímica ou tentar algum outro tipo de comunicação, mas era deste modo que aprendi mais palavras em alemão e até de outras línguas. Não foi apenas com outros países que encontrei diferenças, entre os outros estados havia muitas. Diferenças que iam desde o sotaque até o gosto pelas comidas características de cada região do Brasil.

Todos aqueles que já fizeram ou ainda vão fazer intercâmbio para algum país sempre vão dizer que foi uma experiência que mudou a sua vida. $\mathrm{E}$ essa é uma frase que nenhum ex-intercambista pode dizer que não seja 
verdade, pois é a pura realidade de um intercambista que volta para o seu país. Com o intercâmbio para a Alemanha, eu pude ter um contato com as diferentes culturas, dando ênfase aos nativos alemães que me ajudaram muito no processo de aprendizado do idioma, a conhecer novas pessoas, estimular ainda mais a minha vontade de estudar alemão, querer conhecer novos países e no final ter muitas histórias para contar!

\section{Considerações finais}

Nesse relato, percebe-se a relevância que o ensino das línguas estrangeiras alcançaram como promotoras da variedade cultural e da tolerância, e como o CAp está sintonizado com as necessidades do mundo moderno, aceitando o desafio de concretizar propostas inovadoras, em que os alunos possam estabelecer uma relação com o mundo, ampliando seus horizontes culturais, qualificando a sua formação e preparando-se como cidadãos aptos a se incluir no mundo globalizado. Por meio do conhecimento de novos idiomas e do contato com outros países, a prática do intercâmbio propicia aos alunos uma real oportunidade de vivenciar outras culturas, abrindo novos horizontes e perspectivas para a vida destes jovens.

A língua alemã é, muitas vezes, considerada difícil, especialmente porque as pessoas mistificam as dificuldades, que existem no aprendizado de qualquer língua estrangeira. Sem dúvida, o incentivo recebido através da iniciativa PASCH, Escolas: uma parceria para of futuro, leva mais alunos a optarem pela língua alemã, principalmente pela perspectiva de disporem de modernos materiais didáticos e equipamentos eletrônicos, mas especialmente pela oportunidade de ser contemplado com uma bolsa de estudos na Alemanha. 


\section{Referências}

SCHULEN: Partner der Zukunft. Disponível em: $<$ http://www.pasch-net. de/>. Acesso em: 08 de ago. 2011.

UNIVERSIDADE Federal do Rio Grande do Sul. Colégio de Aplicação. Departamento de Comunicação. Área de línguas estrangeiras. Minuta do termo de renovação de cooperação entre o Colégio de Aplicação da Universidade Federal do Rio Grande do Sul e o Goethe-Institut. São Paulo, 2011.

UNIVERSIDADE Federal do Rio Grande do Sul. Colégio de Aplicação. Departamento de Comunicação. Área de línguas estrangeiras. Projeto ampliação da oferta e da carga horária de língua alemã no CAp. Porto Alegre, 2008.

UNIVERSIDADE Federal do Rio Grande do Sul. Colégio de Aplicação. Departamento de Comunicação. Área de línguas estrangeiras. Projeto ampliação da oferta e da carga horária de língua estrangeira no Colégio de Aplicação da UFRGS. Porto Alegre, 2008.

UNIVERSIDADE Federal do Rio Grande do Sul. Colégio de Aplicação. Departamento de Comunicação. Área de línguas estrangeiras. Termo de cooperação entre o Colégio de Aplicação da Universidade Federal do Rio Grande do Sul e o Goethe-Institut. São Paulo, 2008. 